\title{
Desmitificación del inmigrante alemán en Don Helmuth, el colono de Carlos Fuenzalida Valdivia
}

\section{Demythification of the german immigrant in Don Helmuth, el colono by Carlos Fuenzalida Valdivia}

\begin{tabular}{c} 
JENNIFER M. VALKO \\
\hline East Carolina University. Estados Unidos. \\
valkoj@ecu.edu
\end{tabular}

\section{RESUMEN}

La novela Don Helmuth, el colono (1960) sigue las pautas criollistas para tratar el tema de la colonización alemana en el sur de Chile hacia mediados del siglo XIX. Aunque se publicó hacia el centenario de la llegada de los germanos y es una de las pocas obras en español que describe el proceso de asentamiento de la comunidad, ha sido desatendida por las críticas. Este ensayo analiza el tema de narrativas "míticas" fundacionales para examinar el desarrollo del protagonista, Helmuth Hensau, y demuestra, por una parte, que el texto desmitifica la figura del inmigrante al incluir las actividades delictivas del personaje principal y sus compatriotas, convirtiendo a la novela en suplemento a la historiografía, la cual usualmente omite dichos aspectos negativos. Por otra parte, plantea que estas mismas actividades ilícitas permiten al narrador integrar simbólicamente a los alemanes a su patria adoptiva como un nuevo "tipo" nacional chileno.

Palabras claves: Inmigración, alemanes, construcción nacional, criollismo, Chile, siglo XIX.

\section{ABSTRACT}

The novel Don Helmuth, the colonist (1960) follows the criollista model to treat the subject of German colonization in southern Chile. Although it was published on 
near the centennial of German arrival, and is one of the few works in Spanish that portrays the establishment of the community, it has been largely ignored by critics. This essay analyzes the theme of "mythical" foundational narratives to examine the development of the protagonist, Helmuth Hensau. On the one hand, it demonstrates that the text demythifies the immigrant figure by including the criminal activities of the main character and those of his compatriots, and that the novel supplements historiography by discussing these negative aspects of settlement which are generally omitted. On the other, it proposes that it is precisely these illicit activities that permit the narrator to symbolically incorporate Germans into their adopted homeland as a new Chilean national "type".

Keywords: Immigration, Germans, nation building, criollismo, Chile, nineteenth century.

Recibido: 07-09-2009. Aceptado: 07-03-2010.

Seremos chilenos honrados y laboriosos como el que más fuere. Unidos a las filas de nuestros nuevos compatriotas, defenderemos nuestro pais adoptivo contra toda agresión extranjera, con la decisión y firmeza del hombre que defiende su patria, a su familia y sus intereses. -Juramento de Carlos Anwandter en 1850. (Pérez Rosales [1882] 1970: 487)

Ce aproxima el Bicentenario que conmemora la formación de la nación $\circlearrowleft$ moderna en Chile, cuyo inicio la historiografía nacional sitúa en la Patria Vieja y que se va cimentando a lo largo del siglo XIX. Los estudios clásicos sobre los conceptos de nación y nacionalismo plantean que dichas construcciones emplean diversos elementos para cultivar adhesión e identidad colectiva, tales como territorio geográfico, lengua y etnia, administración política, tradiciones y figuras históricas, e incluso medios de comunicación ${ }^{1}$. Un aspecto vital es la articulación de una historia común con eventos claves que marcan los éxitos y los fracasos de una nación, la que promueve de este modo la cohesión entre conciudadanos. En el año 2008 Chilevisión y la Fundación Futuro colaboraron para producir la

\footnotetext{
${ }^{1}$ Para información más específica sobre el tema, ver Hobsbawm y Ranger (1983), Anderson (1991 [1984]) y McCrone (1998).
} 
serie "Postales Bicentenarias", cortometrajes televisivos de cuarenta segundos de duración dedicados a personajes y acontecimientos fundamentales en la memoria chilena, entre las cuales se incluye un corto que destila y refuerza los datos más conocidos sobre la colonización alemana en el sur del país. Esta postal audiovisual presenta a Bernardo Philippi y Vicente Pérez Rosales como autores de la iniciativa inmigratoria, hace referencia al célebre juramento de Carlos Anwandter y resume los grandes aportes de los germanos a la nación chilena: poblar el sur, abrir caminos, construir ciudades y crear prósperas industrias. Las asociaciones entre el Chile austral y este grupo étnico han adquirido connotaciones míticas, pues sus raíces culturales y contribuciones tangibles se conmemoran en libros, festejos, rutas turísticas, museos y gastronomía ${ }^{2}$. Se repiten asimismo imágenes estereotipadas de la colectividad alemana en otros contextos que conservan y promocionan el patrimonio cultural chileno, como las publicaciones de la Liga Chileno-Alemana, información del Servicio Nacional de Turismo (SERNATUR), la página de la red "Memoria chilena" de la Dirección de Bibliotecas, Archivos y Museos (DIBAM), y números del suplemento escolar "Icarito" del periódico La tercera ${ }^{3}$.

En general, los hitos conmemorativos sirven también para reflexionar y evaluar algunas de las bases que constituyen la identidad nacional. En su libro Identidad y nación entre dos siglos: Patria Vieja, Centenario y Bicentenario, Bárbara Silva Avaria declara a este respecto: "Cuando una situación histórica fundacional adquiere un carácter mítico, se olvidan o al menos se relativizan las contradicciones, ambigüedades, vacíos, arbitrariedades, etc., que son parte tan constitutiva de tal situación como aquello que rescata" (2008: 10). Considerando este hecho, este ensayo examina la imagen de la colonización alemana en Don Helmuth, el colono (1960) de Carlos Fuenzalida Valdivia, novela publicada hacia el centenario de la llegada de los pioneros germanos al sur de Chile. A pesar de ser una de las pocas obras dedicadas al tema,

\footnotetext{
2 Una definición básica de "mito" afirma que es un relato, creencia o convicción sólidamente aceptada que cumple un papel importante para sus seguidores (Segal, 2004: 4-6). Concuerdo también con la especificación que ofrece Smith: "un mito unifica en una visión única y poderosa hechos históricos y elementos de elaboración legendaria para crear un compromiso y un lazo absolutos para una comunidad" (1999: 58; traducción mía).

${ }^{3}$ Fundada en 1916, la Liga Chileno-Alemana se encarga de la conservación de archivos y la circulación de información, historia y prácticas culturales relacionadas con la comunidad chilena de ascendencia alemana. Sus iniciativas incluyen la preservación de la lengua alemana y mantención de buenas relaciones con Alemania (Liga Chileno-Alemana 1991: 20-21; 2002: 5). Ver también Montecino Aguirre (2003) para una meritoria colección de ensayos que cuestionan la(s) identidad(es) chilena(s), sus mitos e historias.
} 
no ha sido estudiada por la crítica académica ${ }^{4}$. Mi hipótesis se desdobla en dos niveles complementarios. Por un lado, en el nivel de la historia, la novela desmitifica la figura del colono germano al revelar las actividades delictivas del protagonista y sus connacionales, que la imagen estereotípica de los alemanes en Chile omite. En el nivel de la narración, por otro lado, la evaluación final del narrador respecto a las actividades de Helmuth integra simbólicamente al colono a su nueva nación y lo propone como un nuevo "tipo" en el catálogo nacional. En las siguientes páginas se presenta la biografía del autor y su obra, se resumen los aportes alemanes en la Región de los Lagos según la historiografía y luego se analiza la narración de los acontecimientos en la novela poniendo especial atención en el desarrollo de su protagonista, Helmuth Hensau, y en el activo papel del narrador en el texto. Para concluir se amplía el tema de la identidad nacional, y en concreto el vínculo entre la modernidad, las minorías y la literatura como instrumento de reflexión cultural.

\section{CARLOS FUENZALIDA VALDIVIA Y SU OBRA}

Escritor y carabinero, el teniente coronel Carlos Fuenzalida Valdivia ha sido celebrado como miembro de un grupo de autores que pertenecen a las Fuerzas Armadas, junto a sus colegas Olegario Lazo Baeza, César Laín Toro y Diego Barros Ortiz (Campaña, 1972: 5). Publicó tres obras principales: Huellas (1953), conjunto de relatos sobre la vida y trabajo de carabineros; Don Helmuth (1960), novela acerca de la colonización alemana que retrata la vida de un inmigrante y su familia en el sur del país; y su último libro $E l$ Capitán Trizano y su gente (1971), relato de las proezas del capitán Hernán Trizano, un "héroe" nacional que lideró el regimiento de los Gendarmes de las Colonias para "pacificar" la Araucanía y combatir el bandolerismo en la zona de la Frontera en el siglo XIX.

En la narrativa de Fuenzalida, los críticos destacan su prosa realista, su empleo de breves viñetas, y su estilo sencillo y fácil de entender. Igualmente subrayan la temática policíaca y criminal, el tratamiento de la justicia y las descripciones de la naturaleza austral (Campaña, 1972: 5; "Estudiantes leerán”, 1972: 14). Mientras se celebra Huellas por su presentación del trabajo de carabineros, los grandes elogios van a su novela histórica El Capitán Tri-

\footnotetext{
${ }^{4}$ Otras obras que tratan el tema son Recuerdos del pasado (1882) de Vicente Pérez Rosales y, sobre la generación posterior a los inmigrantes originales, la novela Ully (1923) de Mariano Latorre.
} 
zano y su gente, la que incluso llegó a ser considerada como texto de lectura para alumnos de tercero y cuarto año medio por la Superintendencia de Educación Pública. Paradójicamente, no existen evaluaciones de Don Helmuth en las discusiones de las obras de Fuenzalida, salvo referencias al título y el año de publicación, y concisas observaciones sobre su tema principal (Vargas Badilla, 1988: 3).

Si bien acotar la línea criollista en la literatura chilena es tarea compleja -hasta polémica- por los diferentes rasgos, grupos y generaciones que detectan historiadores y críticos literarios, se puede afirmar en términos generales que la novela Don Helmuth forma parte de esta tradición ${ }^{5}$. La obra evoca el paisaje, las costumbres y los "tipos" que residen en un ambiente rural chileno. Aspira también a retratar de manera fiel distintos aspectos de la vida agreste considerando los procesos modernizadores y sus efectos en los diversos sectores sociales de la época en que se desarrolla la trama. Comparte además otras características acordes con esta tendencia literaria: la lucha entre el hombre y las fuerzas telúricas; la reproducción léxica u ortográfica del habla de diferentes grupos étnicos y clases sociales; y por último, una clara intención moral y didáctica. En este caso, se presenta cómo el colono alemán contribuye al desarrollo económico y social de una zona específica del país, y cómo se integra a la realidad chilena.

Aunque no proporciona fechas concretas, Don Helmuth traza la vida del protagonista desde mediados del siglo XIX hasta principios del siglo XX enfocándose en el ámbito laboral. Al comienzo Helmuth vive en la ciudad de Hamburgo; es un trabajador frustrado en la carrocería de su padre que desea independizarse de la profesión familiar para "labrarse un porvenir" en el extranjero (1960: 6-7). Por ese motivo, emigra a Chile acompañado de su familia: su esposa, Victoria, y sus hijos Adolf, Harold y Ertna. La novela narra su vida como humilde colono agrícola en Llanquihue y Osorno, y también los actos que facilitan su ascenso social. La historia termina cuando fallece el personaje principal ya trasformado en acaudalado propietario y respetado residente de la comunidad osornina.

La trama se elabora en dos planos narrativos: por una parte, a través de un narrador en tercera persona omnisciente que narra desde fuera del mundo del relato, y, por otra, mediante el diálogo entre los personajes. En varios momentos la voz narrativa interrumpe la historia de Helmuth y sus familiares al intercalar descripciones de estilo costumbrista, las cuales no sólo dan a conocer la vida esforzada de la primera generación de alemanes y los

\footnotetext{
${ }^{5}$ Para un estudio completo sobre el criollismo en Chile, ver Oelker (1983).
} 
cambios que experimenta la colectividad al madurar sus descendientes, sino que también retratan celebraciones "típicas" chilenas, ceremonias mapuche y episodios delictivos relacionados con el bandolerismo, la adquisición de terrenos y el papel de las autoridades regionales. Aparecen asimismo referencias breves a personajes históricos ya legendarios, como Bernardo Philippi, Vicente Pérez Rosales, los industriales Carlos Anwandter (cervecero) y Cristiano Rudloff (curtidor), incluso el infame intrigante Carlos Muschgay $^{6}$. Igualmente hay alusiones a acontecimientos famosos en la historia de la colonización alemana que ayudan a marcar el tiempo en el texto. Para entender mejor la ambientación de la novela, las características prodigiosas adscritas a esta colectividad en el imaginario chileno y la desmitificación del colono alemán encarnado en el personaje de don Helmuth, es preciso esbozar el perfil histórico de los miembros de la comunidad alemana en el sur.

\section{LOS ALEMANES EN LA REGIÓN DE LOS LAGOS}

La imagen mítica comúnmente difundida en los medios de comunicación retrata una colectividad compuesta de inmigrantes alemanes humildes que supera numerosos obstáculos y logra transformar una región "vacía” y silvestre en una zona próspera por su actividad agrícola e industrial. Además subraya cómo un grupo étnico reclutado y subvencionado por el gobierno se radica en Chile y contribuye a la construcción nacional en un momento histórico crítico. Por supuesto, todos estos elementos sirven para reafirmar su integración al país. Aunque esta imagen tiene aspectos verosímiles, da la impresión, sin embargo, que todos los germanos eran iguales, que experimentaron los mismos retos y que en la región sólo había alemanes.

Concluida la guerra de independencia, los grupos dirigentes veían la incorporación de los territorios australes como un aspecto clave de la prosperidad nacional, no sólo para defender la soberanía chilena ante Argentina, sino también para aprovechar las riquezas del territorio. En el período entre la expulsión final de las fuerzas realistas en 1820 y la llegada de los primeros inmigrantes alemanes en 1850, la región sufría una aguda decadencia económica y social por su aislamiento geográfico de los núcleos administrativos del Chile central. Si bien existía una pequeña clase alta en el lugar, ésta no poseía los medios ni la actitud emprendedora para estimular la región (Ber(2008). 
nedo, 1999: 7-9). Es decir, la población local se estimaba reducida y desprovista de la preparación necesaria para generar los resultados deseados por el gobierno: el sembrado de nuevos cultivos agrícolas, la creación de industrias y el desarrollo económico del país en general para conectar dicho territorio con mercados nacionales e internacionales ${ }^{7}$.

Durante la administración del Presidente Manuel Bulnes se promulgó la Ley de Colonización en 1845, la cual formaba parte de un proyecto de construcción nacional más amplio que reclutó activamente inmigrantes alemanes con el fin de "poblar" y "modernizar" la zona. Tanto como en la Argentina de la época, es precisamente la noción de "modernidad" favorecida por la élite dirigente la que identifica a dos grupos minoritarios involucrados de manera diversa en este proyecto: los indígenas como obstáculo al programa nacional y los europeos como pobladores y residentes ideales ${ }^{8}$. En Chile, se anhelaban germanos por varias razones. Primero, Alemania no se percibía como amenaza, ya que estaba dividida y carecía de poder a nivel de política internacional ${ }^{9}$. Además, existían nociones específicas acerca del carácter alemán: laborioso, honesto, respetuoso del orden y la autoridad (Young, 1974: 74). Con el expreso objetivo de atraer a dichos colonos, Chile se promocionaba como destino inmigratorio en Alemania a través de agentes como Philippi y Pérez Rosales ${ }^{10}$. Los primeros grupos de inmigrantes recibieron parcelas y subvenciones del gobierno chileno para asentarse en la patria adoptiva e iniciar su próspera labor.

Entre 1850 y 1880 llegaron aproximadamente 5.100 alemanes al sur de Chile (Young, 1974: 14) ${ }^{11}$. Los historiadores coinciden al describir las carac-

\footnotetext{
${ }^{7}$ Sobre la situación antes y después de la llegada de los germanos a la región, consultar Sánchez (1948), Peralta (1991) y Bernedo (1999).

${ }^{8}$ Un estudio provechoso de los conceptos de "modernidad" (occidental) y "modernidad periférica", y los efectos en la identidad nacional, narrativas de origen y mitología popular en el contexto latinoamericano y global se encuentra en Pratt (2002). Volveré al tema de las minorías en las conclusiones.

${ }^{9}$ Parte de una serie de rebeliones democrático-burguesas en Europa Central, la Revolución de Marzo sacudió al país en 1848. El acontecimiento refuerza las percepciones chilenas acerca de las divisiones, inestabilidad y falta de poder alemanas en el marco internacional. Otro dato significativo es que Alemania no logra unificarse definitivamente sino hasta 1871 (Blackbourn, 2003: 104-131; 171-203).

${ }^{10}$ Ver Young (1974), Blancpain (1985) y Heberlein (2008) para estudios fundamentales sobre el contexto chileno. Chile no era el único país que reclutaba y facilitaba la inmigración germana durante el siglo XIX; Argentina impulsó el mismo plan. Ver Castro (1991), Saint Sauveur-Henn (1995) y Devoto (2003). Investigadores, principalmente del campo de estudios culturales alemanes, se ocupan de los múltiples aspectos relacionados con la cultura germana en el extranjero (más bien en Europa del Este, Estados Unidos, Canadá, Australia, Brasil, México y Paraguay). Excelentes ejemplos de estudios recientes son Krista O’Donnell et al. (2005) y Mathias Schulze (2008).

${ }^{11}$ Me limito a presentar información sobre esta época porque es cuando Helmuth supues-
} 
terísticas principales de esta inmigración alemana y señalan que, a pesar de originarse en diferentes estados alemanes, tenían rasgos importantes en común ${ }^{12}$. Predominaban entre ellos los agricultores y artesanos especializados, marcando así cierta homogeneidad profesional. También, la gran mayoría estaba constituida por familias jóvenes. En contraste con la imagen estereotipada del menesteroso inmigrante alemán que arriba al sur, eran pocas las familias que llegaron con escasos recursos. Por lo tanto, es necesario recordar que poseían capital, herramientas, muebles, ropa, utensilios de casa y otros bienes. Incluso había entre ellos burgueses adinerados, como Carlos Anwandter, que traían su fortuna y otorgaban préstamos a los compatriotas que no disponían de fondos para sus iniciativas (Blancpain, 1985: 73-80; Bernedo, 1999: 10). Es más, poco después de desembarcar, los inmigrantes empezaron a comprar propiedades urbanas y rurales a elevados precios. Entre los agricultores, campesinos y artesanos que se afincaron en la región austral destaca un fuerte deseo de conseguir Selbstständigkeit (independencia económica), es decir, de ser sus propios patrones (Young, 1974: 77). Estrechamente vinculado a este anhelo hay otro factor importante que se observa entre los miembros de la colectividad alemana: la ambición (Blancpain, 1985: 71).

Es cierto que los inmigrantes impulsaron cambios dramáticos en los entornos económicos y sociales de la Región de los Lagos. Refiriéndose a la situación osornina, Víctor Sánchez Aguilera afirma: "la llegada de la gente rubia fué [sic] para Osorno como si se hubiera aplicado una inyección a un cuerpo anémico: nuevas ideas, nuevos métodos, un esfuerzo nuevo" (1948: 167). Patricio Bernedo confirma el impacto positivo que brindaron los proyectos de empresarios industriales alemanes y sus familiares en toda la región al establecer un conjunto de fábricas que utilizó materias primas (agrícolas y forestales) de la zona para manufacturar bienes, con lo que a su vez aumentaron no sólo la demanda de mano de obra sino también los sueldos locales ${ }^{13}$.

tamente llega a Chile. Aunque las cifras cambian debido a que los archivos de estadísticas inmigratorias no son precisos, es posible elaborar estimaciones a partir de varias fuentes (Young 1974: 15). Cabe subrayar que, "en ningún momento los germano-chilenos constituirán más del 5,5\% de la población total de las provincias consideradas 'alemanas' debido al origen de sus propietarios" (Blancpain, 1985: 93).

${ }^{12}$ Ver Young (1974), Blancpain (1985), Bernedo (1999) y Pinto (2003).

${ }^{13}$ Bernedo (1999) examina diversas industrias administradas por alemanes hasta la primera Guerra Mundial y demuestra cómo su fundación desencadenó una explosión en otros sectores de la economía local: las cervecerías facilitaron el cultivo de cebada y la introducción del lúpulo, también aumentaron la demanda de leña; las curtiembres y la fábrica de calzado crearon, como efecto secundario, fábricas de cecinas; las destilerías de alcohol exigieron más cultivo de granos; los astilleros y las compañías de navegación estimularon la demanda de maderas. 
Los investigadores también reconocen los desafíos, especialmente para los colonos que se instalaron en lugares más remotos, y las privaciones que experimentaron y superaron. Llanquihue es el locus por excelencia de los colonos alemanes y quizá el caso más retratado en la historia chilena. A menudo se señala la inexistencia de caminos y la escasez alimenticia que sufrieron los inmigrantes durante los primeros años, así como los robos y ataques de indígenas y bandoleros que sufre la colectividad. Como bien señala JeanPierre Blancpain, las imágenes más comunes de los inmigrantes alemanes se concentran en este grupo y celebran su esfuerzo sobrehumano para vencer aquellas dificultades al construir caminos, despejar bosque y cultivar florecientes campos, y defenderse en momentos de adversidad. Es este tipo de narrativa "mítica" a la que se refiere Silva, porque combina hechos históricos con sucesos embellecidos y conocidos que crean vínculos entre connacionales chilenos y, en este caso, chileno-alemanes.

Ahora bien, para mediados del siglo XIX y principios del XX, la Región de los Lagos, aún considerada fronteriza por el gobierno central en Santiago, se trasformaba una vez más en lo que Mary Louise Pratt llamaría una "zona de contacto", es decir, un espacio en el cual grupos o individuos geográfica e históricamente separados entran en contacto y establecen relaciones continuas que muchas veces implican situaciones de discordancia y desigualdad (1992: 6). Dicha zona aparece caracterizada como un ámbito marcado por negociaciones en múltiples niveles, tanto en relación con tratos económicos como con respecto a la identidad personal o nacional. Es aquella realidad de zona de contacto la que mejor muestra Don Helmuth, pues la novela de Fuenzalida no sólo trata los logros más conocidos de los alemanes en el sur, sino que narra asimismo las relaciones desiguales entre estos inmigrantes y sus vecinos locales, revelando a su paso prácticas heterodoxas ausentes del imaginario nacional que, en el texto, ayudan a aquéllos a realizar sus ambiciones económicas y sociales. Retrata también la formación de una mayoría y una minoría, fenómeno característico del mundo moderno que, según Arjun Appadurai, invita nuevos modos de examinar las obligaciones de estados y los límites del humanitarismo político (2006: 42). Un aspecto importante que la historiografía de los germanos en Chile no profundiza es precisamente el modo como algunos de ellos llegaron a apoderarse de grandes extensiones de campo en Valdivia, Llanquihue y Osorno ${ }^{14}$. De hecho, no es sino

${ }^{14}$ Pérez Rosales describe el impulso especulativo y la adquisición de terrenos por parte de vecinos locales al saber de la llegada de colonos alemanes. Es el único autor que menciona brevemente el engaño a caciques y la corrupción de las autoridades municipales, quienes facilitaban "ventas" y acreditaban títulos, llenando así los archivos públicos de Valdivia (1882: 478-480). Ver también, 
hasta fines del siglo XX y principios del XXI que se esclarecen las prácticas de la compraventa de tierras en aquellos distritos ${ }^{15}$. Es más, los historiadores anteriores utilizan eufemismos para aludir a la especulación y la compra de terrenos a la llegada de los alemanes: "[...] repentinamente casi todos los terrenos más cercanos a Valdivia aparecieron con dueños que sólo ofrecían deshacerse a buen precio de sus propiedades. Todos se hicieron propietarios de las formas más curiosas" (Sánchez, 1948: 168). Si bien los investigadores aluden a prácticas "curiosas" para la adquisición de tierras de parte de los locales, es significativo que sea una novela, Don Helmuth, la que suplementa lo que la historiografía apenas sugería acerca de dicho modus operandi y el activo papel de los germanos en este proceso de transferencia territorial.

\section{EL COLONO EJEMPLAR}

El título, Don Helmuth, el colono, sugiere que el protagonista es un símbolo representativo de todos los colonos alemanes del sur. Su nombre, Helmuth, compuesto de Helm (yelmo o protector) y Mut (coraje), indica su cualidad de "valiente defensor", lo que lleva a preguntarse qué exactamente defiende con tanta valentía el personaje principal. Durante el primer cuarto de la novela, Helmuth Hensau es un colono modelo que coincide con el perfil estereotipado del agricultor germano en Chile. Este artesano deja Hamburgo, acompañado de su familia, como un sencillo trabajador. El narrador confirma su posición de colono típico cuando lo describe considerando la posibilidad de radicarse en otro país:

Varios días le perseguía la idea de emigrar; se había convencido de que el extranjero laborioso, en otras latitudes, hacía fortuna rápidamente. A este propósito, recordaba que algunos de sus compatriotas se encontraban en China, en Brasil, en Argentina, y la buena estrella, invariablemente, les había acompañado; hoy eran respetables y adinerados caballeros (1960: 7).

La voz narrativa da a conocer que Helmuth comparte ideas preconcebidas comunes entre inmigrantes europeos del siglo XIX: si se es laborioso, es posible hacer fortuna y, con un poco de suerte, mejorar la situación social.

Peralta (1991) y Bernedo (1999).

${ }^{15}$ Actualmente Fabián Almonacid (2009) estudia el comercio de tierras por particulares (en general) y expone las sistemáticas irregularidades y el consiguiente desplazamiento de los indígenas de la zona. 
Revela también un prejuicio de parte del alemán: convertirse en "caballero respetable" implica ser "adinerado". El texto construye una imagen positiva inicial del protagonista desde el viaje con su familia en la primordial goleta Hermann, considerada por Blancpain como "el 'Mayflower' de la inmigración alemana en Chile" (1985: 53). En la travesía muestra "sangre fría" ante peligros y logra eliminar tensiones entre sus compatriotas católicos y luteranos. Al llegar a Corral, conoce a Pérez Rosales, intendente de la Provincia, quien le entrega personalmente una hijuela de 300 hectáreas a orillas del Lago Llanquihue (1960: 20). Sufre un largo invierno sacrificado, pero al año siguiente comienza a prosperar en el país adoptivo:

En el segundo año de labor, ya empezaron a cosecharse algunos frutos. Don Helmuth contrató indígenas y chilotes para laborar la tierra. De diciembre a marzo, efectuó el corte de los árboles e hizo funcionar el primer aserradero de la zona. Luego cambió su rancho del primer tiempo por una amplia casa de roble. Construyó graneros, establos, jardines, corrales de ovejas y arboledas frutales. Los potreros fueron sembrados con trigo, nabos, papas y cebadas. Industrializó el aceite y destiló aguardiente (1960: 32).

Llamativo es que no se menciona nunca de dónde consigue Helmuth los fondos para comprar esa gran cantidad de materiales, animales y semillas. Claramente se da por sentado que las subvenciones de gobierno ayudan a costear sus gastos, pero esta sección resalta sobre todo su vigor laboral e implica que su éxito es producto de su propio trabajo. El protagonista es tan laborioso que no sólo cultiva la tierra sino que también echa andar otra empresa clave, un aserradero, como efecto secundario de la construcción de su nueva casa. En ese mismo año produce aceite y aguardiente, y poco después forma una lechería (1960: 37). Esta descripción es netamente hiperbólica, pues señala asimismo que Helmuth instala su taller de carrocería, con el cual "ganó mucho dinero vendiendo el vehículo de trabajo a los demás hacendados" (1960: 47). Notablemente la narración destaca el hecho de que el colono contrata a "indígenas y chilotes" para faenas agrícolas, pero no menciona el modo como ganó o consiguió suficiente dinero para pagar salarios.

Desde el principio, por tanto, la novela marca la presencia de poblaciones que ya vivían en la región y trabajaban como mano de obra, creando así el "contacto" y la relación laboral entre los grupos. La lista de obras realizadas por el personaje principal concuerda con las imágenes de los "industriosos alemanes" y pone énfasis en el trabajo épico efectuado para desarrollar el sur. La inverosimilitud de que un solo hombre pueda ejecutar efectivamente 
tantas funciones se entiende en tanto el protagonista personifica el esfuerzo heroico de todos los miembros de su comunidad. Es imprescindible señalar que, al mismo tiempo, el texto sugiere que el alemán realiza una parte de estas obras con la ayuda de braceros locales, cuya relación con él se transformará más adelante en la historia. En esta primera parte, entonces, el colono se hace "caballero respetado": Helmuth consigue Selbstständigkeit al establecer varias prósperas empresas y acumular capital, y no comete ningún acto que contradice su honradez. Es más, según la opinión del narrador, el inmigrante inspira respeto (1960: 51). De ahora en adelante, sin embargo, la imagen míticamente positiva de Helmuth sufre un cambio significativo porque sus acciones se desvían del relato estereotípico de los alemanes en el Chile austral.

\section{DON HELMUTH EN TELA DE JUICIO}

Ya cómodamente asentado, Helmuth concibe un objetivo nuevo: dejarle una hacienda a cada uno de sus tres hijos (1960: 59). A partir de este punto, el texto enfatiza los medios ilícitos empleados por el protagonista para realizar dicha meta, los cuales constituyen en buena parte aquellas "formas curiosas" de apropiación de la comunidad alemana que la historiografía apenas menciona: el robo, el asesinato, la estafa, el soborno y la explotación de autoridades corruptas. En Don Helmuth, estas prácticas no sólo revelan las relaciones de poder entre, por un lado, europeos, representantes gubernamentales y judiciales chilenos, y, por otro, mapuches, mestizos y chilotes locales, sino que también, y como consecuencia, ponen en duda la integridad de la colectividad germana representada por el protagonista.

La odisea delictiva de Helmuth se inicia con la reacción del colono cuando el cacique Peñalemuñín le pide la mano de su hija, Ertna, de trece años de edad: "Esta proposición le tomó de sorpresa a don Helmuth, y como es natural, se opuso a tal oferta y le despidió con buenas palabras, mientras en su cerebro maduraba la idea de cómo podría apropiarse de su campo" (1960: 56). Las "buenas palabras" se traducen en "buenas obras", en el sentido de que el protagonista pone en práctica un plan a largo plazo para conquistar la confianza del cacique al comprarle la cosecha a buen precio y prestarle dinero (1960: 48). Se observan las maquinaciones del alemán cuando Peñalemuñín le solicita un préstamo cuantioso:

Don Helmuth no tuvo inconveniente en prestarle la suma de diez mil 
pesos, con garantía hipotecaria de la finca. En la notaría dejó redactada la escritura en forma que agregándole un cero a la cantidad prestada, podía convertirse en la deuda de cien mil pesos. Quedó así mismo en blanco un espacio para escribirla también en letras (1960: 58).

Esta anécdota revela la manera en que el colono utiliza caminos legales para abusar de un mapuche analfabeto subiendo ilegalmente el monto prestado y agregando la hipoteca de la finca. Aunque el narrador no provee más detalles, el hecho sugiere que el notario era cómplice de Helmuth, puesto que, al dar fe del contrato, el funcionario público debió confirmar la suma correcta según el acuerdo entre los signatarios. El cacique no tiene los recursos para pagar la deuda, pero repetidas veces se niega a entregar "las tierras de sus antepasados". Frente a esa situación, el protagonista contrata a un "feroz cuatrero" apodado el "Lacho de las Mulas" para asesinar a Peñalemuñín (1960: 58). Liquidado el cacique, el narrador describe cómo Helmuth se apodera de sus propiedades:

El juez ordenó a la policía levantar el cadáver. Inútilmente los mapus [sic] clamaron justicia. El alemán obtenía así, tres mil hectáreas más. Con este suculento aporte y con las tierras que el Fisco le había entregado, aumentó su haber a la cantidad de tres mil trescientas hectáreas. Don Helmuth presentó oportunamente al Juzgado los documentos que le otorgaban derecho a tomar posesión del predio de Peñalemuñín, y obtuvo, como es natural, una resolución favorable (1960: 59).

Los lectores son testigos de esta zona de contacto impregnada de corrupción. No hay investigación de la muerte del cacique, a pesar de las protestas de la comunidad mapuche. Por otro lado, nadie refuta los documentos que presenta el alemán al Juzgado. Muy por el contrario, el texto indica que el personaje principal "obtuvo, como es natural, una resolución favorable". Este comentario del narrador puede ser interpretado de dos maneras: primero, que Helmuth recibe los terrenos porque posee la documentación pertinente y, segundo, que el engaño legalizado es común y "natural” entre patrones y colonos, los que reciben tratamiento y protección especial de las autoridades chilenas ${ }^{16}$.

\footnotetext{
${ }^{16}$ Aunque el historiador José Bengoa (1996) estudia principalmente las regiones del Bío-Bío y de la Araucanía, ofrece información esencial para entender las prácticas de adquisición de propiedades indígenas durante los siglos XIX y XX. Explica que los indígenas no tenían un "criterio mercantil" para valorar sus terrenos y que esta situación facilitaba la apropiación por parte de especula-
} 
En esta nueva etapa de su vida, Helmuth no discrimina entre sus víctimas, pues también se aprovecha de los chilenos locales. Descubre el comportamiento derrochador de Roberto Mora, joven heredero de un fundo con tierras muy productivas y amigo íntimo de su hijo Harold. El protagonista hace que éste abuse de la confianza de su compañero exigiéndole que lo espíe. Cuando Harold le comenta a su padre que Roberto está en precaria situación económica, Helmuth saca de apuros a Mora al comprarle la hacienda. El narrador observa: "todo lo ejecutó éste [Helmuth] rápidamente, a fin de no despertar recelos entre la gente maliciosa, ya que apenas pagó a su dueño la cuarta parte de su valor real" (1960: 87). En síntesis, para conseguirle una propiedad a un descendiente directo, Helmuth estafa al mejor amigo de uno de sus hijos.

Para apoderarse de la última finca, el protagonista necesita el respaldo de altas autoridades. La novela trata el tema de la corrupción política y judicial resaltando el hecho de que dicho comportamiento es aceptable y posible sólo para los residentes que puedan financiar relaciones quid pro quo. A tal efecto, Helmuth busca amigos políticos dispuestos a proteger "el patrimonio de personas que, como él, ya habían amasado una regular fortuna" (1960: 72). Apoya al candidato del partido Conservador en su campaña para el Senado con donaciones monetarias y la entrega de los votos de su peonada (1960: 72). Cuando el candidato gana, el narrador declara: "Don Helmuth exultaba de felicidad. Nuestro buen alemán contaría en adelante con santos en la corte" (1960: 73). La expresividad del narrador se relaciona asimismo con otro poder institucional al que apela el personaje, pues, ya que disponía de una gran fortuna, Helmuth, como buen vecino, paga "primicias" (contribuciones) a la Iglesia, se hace socio benefactor del Club donde se reúne con autoridades de la región y dona dinero a instituciones gremiales y caritativas (1960: 90). A cambio de su apoyo político y financiero a numerosas personas y organizaciones, el colono recibe ciertos privilegios que le abren el camino para lograr sus objetivos.

El tercer fundo que consigue Helmuth para su familia es propiedad del indio Colún. En este punto de la historia, el texto explicita: "La complicidad de la politiquería, de las altas y bajas autoridades, era sin restricciones"

dores y militares; no obstante, se permitían transacciones directas entre mapuches y particulares, y frecuentemente surgieron conflictos. Según Bengoa, mientras avanzaba la colonización extranjera se complicaba aún más la situación. Con el fin de normalizar la compra y venta de terrenos amerindios se promulgó la Ley del 14 de marzo de 1853: "Entre 1853 y 1866 esta legislación reguló los procedimientos, aunque la compra de tierras y el engaño a los vendedores continuó, ahora con el beneplácito de las autoridades locales" (1996: 157-159). Almonacid confirma y profundiza tales prácticas (2009: 10; 15-16;22). 
(1960: 90). Para usurpar los terrenos de Colún, el alemán acude al Ministerio de Tierras, donde obtiene una orden de enajenación y la ayuda de soldados para cumplir el mandato. La novela destaca la violencia de la situación: la repentina llegada de una tropa armada a la morada de un mapuche y su familia para despojarlo $s$ de sus dominios por la fuerza. En la opinión del narrador, la orden "[...] no constituía sino un brutal despojo" (1960: 90). La voz narrativa recalca el hecho de que la amenaza es contra una familia con mujeres y niños presentes, y que también hay testigos. Frente a dicha provocación, Colún y los suyos optan por defender su familia y bienes. Ambos bandos poseen armas y se inicia un tiroteo que acaba de la siguiente manera:

Y así, ante la tenaz resistencia de los indios, el oficial no tuvo otro remedio que incendiar la ruca. Cuando el fuego tomó cuerpo y las llamas amenazaban abarcarlo todo, las personas allí refugiadas fueron saliendo una por una; pero a medida que iban apareciendo eran diezmadas bárbaramente por las balas de los trizanos. Se cruzaba el acero, portando dolor, odio y muerte. Cayó en la refriega Colún, en primer lugar; le siguió su mujer, tres hijos, y por último sus dos amigos. Sobrevivieron, un indiecito de doce años y una chica de catorce. Poco antes de expirar, se oyó la voz lastimera de Colún, que entre las garras de la muerte, protestaba: — ¡Chileno y alemano [sic], bandíus [sic], ...robaron tierra y ruca mía! Los dos indiecitos huérfanos los tomó a su cargo don Helmuth y los mandó a educarse a la misión de los padres capuchinos del sur (1960: 91-92).

El acto de usurpación impulsado por Helmuth termina en la masacre de una familia mapuche local. Aparte de conseguir los documentos y la aprobación del Ministerio de Tierras, el colono no necesita intervenir en absoluto, para eso la ley y los soldados actúan por él. Las últimas palabras acusatorias de Colún aluden a la presencia del personaje principal en el lugar de la matanza e igualan a chilenos y alemanes como criminales cómplices. La usurpación de tierras indígenas en todo el sur es una práctica bien documentada en denuncias publicadas en periódicos regionales chilenos durante las primeras tres décadas del siglo $\mathrm{XX}^{17}$. El episodio novelesco confirma que inmigrantes pudientes como Helmuth son protegidos por las autoridades. Es más, implica que los alemanes respaldados por la ley forman parte de un

${ }^{17}$ Para información específica y descripciones de casos cometidos por alemanes en Llanquihue, Frutillar y Osorno, consultar Bengoa (1996: 372-377). 
plan a nivel gubernamental para ocupar los territorios australes, "pacificar" la llamada Araucanía y "consolidar el país", objetivo que incorpora a los inmigrantes a la nación y los utiliza para desplazar y desapropiar a los residentes históricos ${ }^{18}$.

\section{HELMUTH COMO REPRESENTANTE DE LA COMUNIDAD ALEMANA}

Helmuth no sólo comete crímenes para asegurar y defender la posición económica y social de su familia sino que también actúa por el conjunto de la comunidad alemana y otros terratenientes de la región. Aunque las autoridades saben que los hacendados negocian y amparan cuatreros, el jefe de los trizanos aboga por eliminar esta forma de delincuencia y logra recibir una orden directa del juez para este efecto. Surge un "problema" grande para todos los residentes de la zona. Los guardias invaden el campo e inspeccionan a la fuerza desde las rucas más humildes hasta las residencias más opulentas. La redada de los trizanos no discrimina; capturan y también matan a "inocentes y culpables, ricos y pobres" (1960: 75). Los uniformados inspiran tanto miedo que incluso los cuatreros huyen del lugar. Los terratenientes le encomiendan a Helmuth buscar una solución, y éste contrata al cuatrero "Lacho de las Mulas", a quien escondía en el sótano de su casa en Osorno. El colono le explica el plan así al cuatrero:

-Oye amigo, tienes que hacegme un tgabajito...

- ¿Cuál será patroncito?

Don Helmuth, mirando a uno y a otro lado e indicándole silencio, le explicó:

—Tenemos que liquidag al Juez; está molestando demasiado. Tú, más que nadie, peligras, pues cuakquieg día te mandan a Cantón... Además, si esto sigue, no te podré proteger, y se acabará para siempre el negocito de animales que aprovechamos desde hace tantos años.

El Lacho de las Mulas asintió en el mismo tono.

—Clarito pus, patrón, que me tiraré el salto, pus. Rejodida la cosa, matar a Usía.

(1960: 76; negrilla y transcripción fonética en el original)

${ }^{18}$ La investigación de Almonacid recalca el interés estatal en asentar chilenos y extranjeros en la región, y tratar por igual a ambos grupos en la distribución de hijuelas por sobre los intereses indígenas (2009: 14). Véase también Jorge Pinto (2003) para un valioso estudio de este tema. 
Esta sección manifiesta la reproducción ortográfica y léxica de diferentes elementos sociales: un inmigrante germano con acento español y un chileno del campo. El uso de diminutivos demuestra que los interlocutores entienden la naturaleza y gravedad del plan. El diálogo entre Helmuth y el Lacho de las Mulas no sólo revela que el alemán alberga y colabora regularmente con criminales como práctica comercial, sino que también es capaz de asesinar para conservar sus intereses económicos y los de sus "amigos", ya sean hacendados o bandidos. Al hacer matar al juez, Helmuth logra suspender la represión policial y asegurar que se cambie el jefe de trizanos por uno corrupto que se transformará en su "dócil instrumento" (1960: 78-79). Este no es sin embargo el primer caso en que se acude al colono para conseguir auxilio.

Federico Paulsen, amigo alemán de Helmuth, se hace rico en Río Negro, Argentina, pero tiene problemas con las autoridades. Paulsen visita al colono pare pedirle consejos sobre "la tramitación de unos expedientes" en su contra en el Juzgado de Letras de Osorno (1960: 136). Según el narrador, el amigo del protagonista cometió tres delitos: comprar vacas robadas a un cuatrero; apoderarse de un fundo que pertenecía a un cacique viejo y enfermo; y robar y matar a un obrero chilote (1960: 136). Helmuth le da dos ideas: robar los archivos o quemar el edificio del Juzgado, y el narrador confirma la decisión tomada: "Se adoptó este último recurso, por cuanto resolvía también el mismo problema de otros compatriotas; pues tal especie de pecadillos era muy común entre los colonos" (1960: 137). El uso del impersonal de parte del narrador pone énfasis en la decisión, no en quién la tomó, y sugiere que los personajes están conscientes de casos parecidos en contra de otros inmigrantes y de los múltiples beneficios del plan propuesto para toda la comunidad. Por otro lado, implica la complicidad de Helmuth cuando Paulsen contrata a un criminal que lleva a cabo el "recurso" de incendiar el Juzgado (1960: 137-139).

Irónicamente, el camino delictivo de Helmuth no termina sino hasta que logra aniquilar a sus cómplices cuatreros con la ayuda de las autoridades. Este hecho final elimina la posibilidad de que sus viejos colaboradores lo chantajeen y le permite consolidar su imagen como colono y vecino honesto. No obstante, sumando los crímenes del protagonista, él es responsable de la usurpación de dos propiedades indígenas, la adquisición de un fundo por estafa, el incendio de un edificio público y el asesinato de doce personas que incluyen al cacique Peñalemuñín, un juez, el indio Colún, su familia y dos amigos, y el Lacho de las Mulas. Todos estos hechos lo ayudan a prosperar económicamente, a cambiar de posición social, a defender los intereses 
de su familia y de los miembros de la colectividad alemana, y también a proteger los negocios de sus amigos hacendados (alemanes o chilenos) de la región. Ante esta serie de obras, es preciso examinar la actitud del narrador de la novela.

\section{DE NARRADOR MORALIZANTE A PRAGMÁTICO}

El narrador es omnisciente, heterodiegético y toma distancia de la acción al usar el tiempo pasado. La siguiente descripción de una fiesta campestre "a la chilena" ofrece datos adicionales relevantes: "La cueca, nuestro baile popular, fue danzada con entusiasmo por las parejas que trataban de demostrar su destreza. El baile era, para esta gente, como expresión de su felicidad" (1960: 67). Este fragmento no sólo pone de manifiesto la nacionalidad común del narrador, los personajes y los lectores implícitos, sino que a la vez marca una diferencia social y geográfica con el mundo del colono: al definir la palabra "cueca" como baile "popular" la voz narrativa resalta su conocimiento y distancia del campo, y se distingue estamentalmente de "esta gente" campesina. En cuanto al protagonista, reiteradamente el narrador revela y evalúa los pensamientos y acciones del colono. Tras apropiarse de las tierras del cacique Peñalemuñín, describe el estado emotivo de Helmuth:

La mejora de fortuna no calmó, sin embargo, la ambición del colono, y fue acicate para coronar su ambición. Deseaba poseer más y más tierras. Se le había metido entre ceja y ceja dejar una hacienda a cada uno de sus hijos. Recordaba que para él fue dura la vida y trataría de evitar a toda costa que sus descendientes corrieran una suerte parecida. Quería asegurarles un venturoso porvenir. Los medios no le importaban: para él, el fin justificaba los medios (1960: 59).

El narrador explica tanto el origen de su ambición como de su forma de actuar: el fin justifica los medios. Este principio se convierte en la medida con la cual valora las obras de la vida de Helmuth. Mientras se desarrolla la historia y se intensifican los actos delictuosos, el narrador sugiere que el personaje tiene una falla que expresa en términos casi médicos: "La codicia incontrolada le arañaba sus entrañas [...]. Era como el rico que desea mayor riqueza" (1960: 86). La falta de este alemán católico y practicante tiene asimismo connotaciones pecaminosas y, por tanto, dispensable sólo mediante perdón religioso. 
Al final de su vida, Helmuth es dueño de una fortuna y una mansión en Osorno, y en dos momentos críticos el narrador lo retrata en acto de reflexión demostrando que está consciente y arrepentido de cometer actos ilícitos (1960: 119, 165-166). Después de tener un infarto y sentir su mortalidad, se describe al protagonista así:

Don Helmuth, en su quietud prolongada meditaba hondamente sobre toda la trayectoria de su vida y hacía un análisis minucioso para sopesar sus buenas y sus malas acciones. [... .] De todas maneras pensaba, he realizado una obra humana que será entregada al juicio de Dios y de los hombres. Pero el remedio para tales escrúpulos estaba en el confesionario. Así lo hizo, llamando apresuradamente a su amigo el cura Don Antonio. Quizás le bastaría este expediente para sacarse de encima sus culpas. Curioso y sencillo método para lavar la conciencia de la roña y mezquindad humana (1960: 165-166).

Aunque destaca el remordimiento del personaje principal, el narrador cuestiona que el "método" institucional católico de absolución, administrado además por uno de sus amigos, no sólo logre librarlo de su mala conciencia sino que también borre la historia de violencia e ilegalidad que el mismo narrador ha documentado sistemáticamente para el lector.

Ahora bien, aunque describe los motivos, las prácticas criminales y la crisis de conciencia de Helmuth, y la efectividad del perdón religioso, el narrador expresa una segunda opinión al final de la novela que contradice lo anterior. Cuando muere el colono, ofrece una evaluación conclusiva doblemente favorable:

La noticia de su trance se expandió rápidamente y estremeció a la región; se había tronchado la vida de un gran hombre de trabajo. Su empuje y vigor fueron ciclópeos. De una inteligencia clara y profética. [. . .] La colonización del sur, especialmente de su región, la tomó como suya; a todos los colonos los ayudó en el momento oportuno. Tomado en cierto sentido, no fue un egoísta, fue un patriota que hizo lo posible para que triunfara la obra en que se había empeñado. Los hombres de negocios, latifundio y la prensa rindieron un buen homenaje a la memoria del esforzado colono. En los discursos del campo santo, se dijo de él que había sido un patriarca, un pioneer del progreso. El Gobierno se hizo representar en los funerales. El comercio cerró sus puertas y la banda de músicos del pueblo encabezó el largo cortejo (1960: 195). 
La clausura del relato presenta "la obra humana" de Helmuth "entregada al juicio de los hombres". Esta segunda evaluación pone ante el lector la opinión final del narrador mezclada con la de dos grupos sociales en la historia, el público general y la clase dominante, dejando totalmente fuera a las víctimas de las acciones del protagonista. En primer lugar, paradójicamente, la misma voz narrativa chilena que a lo largo de la novela critica los crímenes del personaje lo juzga de manera positiva. Presenta sus virtudes, trabajo, empuje, vigor e inteligencia, en tanto que inscribe en el personaje características sobrehumanas calificándolo de ciclópeo y profético. Esta descripción concuerda con aquellas imágenes estereotipadas mencionadas antes de los alemanes en el imaginario nacional. Si bien el narrador ha retratado los delitos de Helmuth, recalcando el daño que ha causado su ambición, ahora niega su egoísmo y lo declara "patriota" porque facilitó el éxito del proyecto nacional de colonización del sur. En efecto, el narrador chileno parece encontrar los méritos del protagonista evaluándolo según el mismo principio rechazado inicialmente de que el fin justifica los medios. El narrador parece aprobar por tanto los crímenes cometidos porque resultan en el desarrollo del Chile austral.

En segundo lugar, curiosamente se borran los rasgos del sur como zona de contacto y los lectores reciben una descripción del aprecio por el colono de parte de los miembros más privilegiados de la comunidad local -negociantes, hacendados, periodistas- más algún representante gubernamental, quienes lo declaran "patriarca" y "pioneer del progreso". El duelo al que adhiere el comercio local representa uno de los ámbitos que más se benefició de las acciones de Helmuth, a quien se le reconoce como líder de una familia y de una comunidad étnica regional, y hombre modelo para la colectividad. Todo esto explica también el "don" libre de sarcasmo que acompaña el nombre del protagonista en la historia y el título de la novela. En suma, el narrador reconoce, consigna y aprueba en segunda instancia su papel en el desarrollo de la región dentro de las expectativas oficiales del Estado chileno.

\section{CONCLUSIONES}

Don Helmuth, novela publicada alrededor del centenario de la llegada de los alemanes en el Chile austral, da pie a una reflexión sobre el imaginario nacional chileno y los mecanismos de construcción nacional ante el Bicente- 
nario, y obliga a reconsiderar el famoso juramento de Carlos Anwandter ${ }^{19}$ :

Seremos chilenos honrados y laboriosos como el que más fuere. Unidos a las filas de nuestros nuevos compatriotas, defenderemos nuestro país adoptivo contra toda agresión extranjera, con la decisión y firmeza del hombre que defiende su patria, a su familia y sus intereses (Pérez Rosales [1882] 1970: 487).

Esta promesa declarada ante Vicente Pérez Rosales, representante del Estado encargado de recibir e instalar a los colonos en sus parcelas cuando arriban a Valdivia, es un acontecimiento importante de la historia chilena y continúa vigente entre los chileno-alemanes hoy en día. La Liga ChilenoAlemana la considera una "doble unión" a la "patria" de los antepasados y el "país adoptivo" (1991: 6-7). Para la época de la colonización en la que se sitúa la novela, este juramento es de especial interés.

Siguiendo las pautas de la tradición criollista, Don Helmuth retrata las tradiciones y los "tipos" representativos del ambiente rural chileno y muestra los efectos modernizadores en los distintos grupos sociales locales. Representa y al mismo tiempo subvierte la imagen comúnmente difundida de los colonos germanos en el sur, como una colectividad de artesanos humildes que sufrió privaciones, pero que, con su conocimiento y gran empeño, superó grandes obstáculos heroicamente para transformar una región decaída en floreciente y dinámica. Delínea también el perfil del ambicioso inmigrante alemán que defiende a su familia e intereses para asegurar su independencia económica y mejorar su posición social.

Con finalidad moral y didáctica evidente, el narrador cuenta la historia de un colono ejemplar para enseñarle a su público lector chileno los procesos de colonización en aquella región desde mediados del siglo XIX hasta las primeras décadas del siglo XX. No sólo se limita a presentar la historia tradicional "mítica" reiterada en la historiografía, museos, guías turísticas y otras fuentes oficiales, sino que profundiza en los aspectos heterodoxos del asentamiento desatendidos en dichas fuentes oficiales, tales como las relaciones desiguales entre los colonos y los residentes originales mapuches,

${ }^{19}$ Figura importante en la historia de los alemanes en Chile. Farmacéutico, alcalde (Kalau, Prusia) y diputado en el parlamento prusiano antes de su llegada al país, formaba parte de una generación de liberales que salió de Alemania después de la fracasada revolución democrática de 1848. Representando a los alemanes que llegaron con él, enuncia esta promesa de lealtad ante Pérez Rosales indicando su agradecimiento por acogerlos y dejarlos seguir sus convicciones políticas (Blancpain, 1985: 53-56). Dicha promesa forma parte tanto del discurso oficial chileno como de las publicaciones de asociaciones chileno-alemanas. 
mestizos, chilotes; las situaciones de discordancia y tensión; la corrupción pública; y las costumbres delictivas toleradas por buena parte de la sociedad local y el gobierno nacional. En su narración del entorno austral como zona de contacto, el texto desmitifica al colono germano al revelar su complicidad en prácticas criminales para lograr objetivos socio-económicos.

Considerando la intención de emular la honradez y el esfuerzo laboral de los chilenos en la promesa de Anwandter en representación de la comunidad alemana, la novela invierte la imagen de los chilenos al sugerir que los colonos imitan también la inmoralidad y prácticas laborales de sus nuevos compatriotas en su proceso de aculturación. Estas costumbres ponen en duda la integridad tanto de los chilenos (oficiales y hacendados) como de la colectividad germana representada por Helmuth y sus amigos. Paradójicamente, son estas mismas acciones "patrióticas" justificadas por su fin y aprobadas por representantes gubernamentales y sociales, y por el narrador al final del relato, las que integran al protagonista y los demás colonos alemanes como nuevo "tipo" en el catálogo literario nacional. La imagen ambigua de chilenos y alemanes que se desprende de la lectura del texto explica quizás la desatención crítica con respecto a esta novela, la que complementa significativamente el registro histórico de los complejos, y con frecuencia controvertidos, procesos de colonización oficial en el sur del país.

Finalmente, volviendo al planteamiento de Silva acerca de aprovechar una ocasión conmemorativa para reevaluar algunos fundamentos de la identidad nacional y el carácter mítico que adquieren ciertos momentos históricos, la lectura de Don Helmuth sirve como instrumento de reflexión que va más allá del contexto chileno o chileno-alemán, pues recuerda la fuerte influencia del tropo de la "modernidad" occidental, de sus efectos a nivel latinoamericano y global en los siglos XIX y XX, y las implicaciones de la palabra "progreso" para el siglo XXI. Un punto de partida para dicha reflexión es la investigación de Appadurai sobre la creación de minorías, una categoría socio-demográfica reciente producto de la época moderna y del impulso persistente de hostigar a tales grupos (2006: 39-40). Argumenta Appadurai que las minorías representan los fracasos y la coacción en la producción de los estados, y que por tanto éstas llevan consigo los recuerdos de actos de violencia desechados por la historia oficial para legitimarse. Son en efecto el locus para desplazar ansiedades de muchas naciones sobre su propio papel minoritario (real o imaginado) a nivel mundial (2006: 42-43). La novela de Fuenzalida estimula entonces una reevaluación de la interacción entre pueblos originarios y minorías inmigratorias, y las obligaciones gubernamentales respecto al pasado fundacional y el porvenir de nuevos paisajes 
culturales nacidos de los procesos de migración y desplazamiento voluntario y forzado de etnias locales y extranjeras.

\section{REFERENCIAS}

Almonacid Z. Fabián. 2009. "El problema de la propiedad de la tierra en el sur de Chile (1850-1930)", en Historia 42, 1, pp. 5-56.

Anderson, Benedict. 1991 [1984]. Imagined Communities: Reflections on the Origin and Spread of Nationalism. $2^{\mathrm{a}}$ edic. Londres: Verso.

Appadurai, Arjun. 2006. Fear of Small Numbers: An Essay on the Geography of Anger. Durham: Duke University Press.

Bengoa, José. 1996. Historia del pueblo mapuche (siglos XIX y XX). 5a edic. Santiago: Ediciones Sur.

Blackbourn, David. 2003. History of Germany 1790-1918. The Long Nineteenth Century. $2^{\text {a }}$ edic. Oxford: Blackwell.

Blancpain, Jean-Pierre. 1985. Los alemanes en Chile: (1816-1945).Trad. Luis Enrique Jara. Santiago: E.P.C.

Bernedo Pinto, Patricio. 1999. "Los industriales alemanes de Valdivia 18501914”, en Historia 32, pp. 5-42.

Campaña, Antonio. 1972. "Carlos Fuenzalida Valdivia: El Capitán Trizano y su gente", en Última hora, 7 noviembre, p. 5.

Castro, Donald S. 1991. The Development and Politics of Argentine Immigration Policy 1852-1914. To Govern is to Populate. Tesis doctoral. San Francisco: Mellon Research University Press.

"Colonización alemana en Valdivia y Llanquihue (1850-1910)". 2008. Memoria chilena. Portal de la cultura de Chile. DIBAM. 25 mayo 2010. [En línea] Disponible en: www.memoriachilena.cl. [Consulta: 03/04/2010]. "Colonización alemana”. 2008. Postales bicentenarias. Fundación Futuro. 25 mayo 2010. [En línea] Disponible en: www.fundacionfuturo.cl. [Consulta: 03/04/2010].

"Colonizador alemán. Carlos Anwandter". Icarito. Latercera.com. 25 de mayo 2010. [En línea] Disponible en: http://icarito.tercera.cl/medio/articulo/0,0,38035857_357164735_1,00.html. [Consulta: 03/04/2010].

Devoto, Fernando. 2003. Historia de la inmigración en la Argentina. Buenos Aires: Editorial Sudamericana.

"Estudiantes leerán vida del Capitán Trizano". 1972. La tercera, 9 enero, p. 14. Fuenzalida Valdivia, Carlos. 1960. Don Helmuth, el colono. Santiago: Escuela Nacional de Artes Gráficas. 
. 1971. El Capitán Trizano y su gente. Santiago: Imprenta de Carabineros.

Heberlein, Regine I. 2008. Writing a National Colony: The Hostility of Inscription in the German Settlement of Lake Llanquihue. Amherst, N.Y.: Cambria Press.

Hobsbawm, Eric y Terence Ranger. 1983. The Invention of Tradition. Cambridge: Cambridge University Press.

Latorre, Mariano. [1923] 1943. Ully. 2a edic. Santiago: Editorial Nascimiento.

Liga Chileno-Alemana. 1991. Chile y los alemanes. Santiago: Liga ChilenoAlemana.

. 2002. Pioneros del Llanquihue (1852-2002): Edición conmemorativa de los 150 años de la inmigración alemana a Llanquihue. Santiago de Chile: Liga Chileno-Alemana.

McCrone, David. 1998. The Sociology of Nationalism. Londres: Routledge. Montecino Aguirre, Sonia. 2003. Revisitando Chile: Identidades, mitos e historias. Santiago: Publicaciones del Bicentenario.

O’Donnell, Krista, Renate Bridenthal y Nancy Ruth Reagin, eds. 2005. The Heimat Abroad. The Boundaries of Germanness. Ann Arbor: University of Michigan Press.

Oelker, Dieter. 1983. "El criollismo en Chile", en Acta Literaria 8, pp. 3751.

Peralta Vidal, Gabriel. 1991. Historia económica y urbana de Osorno. Osorno: Impresur.

Pérez Rosales, Vicente. [1882] 1970. Recuerdos del pasado (1814-1860). Buenos Aires: Editorial Francisco de Aguirre.

Pinto Rodríguez, Jorge. 2003. La formación del estado y la nación, y el pueblo mapuche: De la inclusión a la exclusión. Santiago: Dirección de Bibliotecas, Archivos y Museos.

Pratt, Mary Louise. 1992. Imperial Eyes. Travel Writing and Transculturation. Londres: Routledge.

. 2002. "Modernity and Periphery. Toward a Global and Relational Analysis". Elisabeth Mudimbe-Boyi, ed. Beyond Dichotomies: Histories, Identities, Cultures and the Challenge of Globalization. Albany, N.Y.: SUNY Press. pp. 21-45.

Saint Sauveur-Henn, Anne. 1995. Un siècle d'émigration vers l'Argentine. Colonia: Böhlau Verlag.

Sánchez Aguilera, Víctor. 1948. El pasado de Osorno. La gran ciudad del porvenir. Osorno: Cervantes. 
Schulze, Mathias (ed.) 2008. German Diasporic Experiences. Identity, Migration, and Loss. Waterloo, Ontario: Wilfrid Laurier University Press.

Segal, Robert A. 2004. Myth. A Short Introduction. Oxford: Oxford University Press.

Silva Avaria, Bárbara. 2008. Identidad y nación entre dos siglos: Patria Vieja, Centenario y Bicentenario. Santiago: LOM Ediciones.

Smith, Anthony. 1999. Myths and Memories of the Nation. Oxford: Oxford University Press.

Vargas Badilla, José. 1988. "Adiós a Carlos Fuenzalida Valdivia", en La región [San Fernando], 5 julio, p. 3.

Young, George F. W. 1974. The Germans in Chile: Immigration and Colonization, 1849-1914. Staten Island, N.Y.: Center for Migration Studies New York. 